\title{
ĐÁNH GIÁ ĐA DẠNG THÀNH PHẦn LOÀI THỰC VậT VÀ NGUYÊN NHÂN \\ LÀM SUY THOÁI THẢM THỰC VẬT Ở HUYỆN VỊ XUYÊN, TỈNH HÀ GIANG
}

Evaluation of diversity of flora species composition and reasons causing vegetation degradation

ThS. Hoàng Thị Hường*, TS. Đỗ Khắc Hùng*

\section{TÓM TÁT}

Trong 3 kiểu thảm thực vật (thảm cỏ, thảm cây bụi, rùng thư sinh) đã thống kê được 557 loài thuộc 393 chi, 114 ho của 5 ngành thục vật bậc cao có mạch: ngành Thông đất, ngành Cỏ tháp bút, ngành Dưong xỉ, ngành Thông và ngành Ngọc lan. Trong đó 15 ho có tù 10 loài trở lên (chiếm 42,01\% tổng số loài), có 13 chi có tù 4 loài trở lên (chiếm 12,39\% tổng số loài), có 33 loài thục vật quý hiếm có trong Sách đỏ Việt Nam (2007) và 7 loài được ghi nhận trong Nghị định 32 của Chính phủ. Phần lớn các loài cây thống kê được đều là các loài tiên phong ưa sáng vì có thể bắt gặp chúng moc trên đất sau khai thác kiệt, trên các chỗ trống của rùng sau khi nhũng cây gố lớn bị chặt hạ. Tuy có thành phần thực vật phong phú và đa dạng nhưng thảm thực vật ở huyện Vị Xuyên lại đang bị suy giảm đáng kể cả về diện tích và chất lượng mà nguyên nhân chủ yếu là do các hoạt động khai thác gố, thai thác củi, khai thác lâm sản ngoài gố khác và cháy rù̀ng...

Tù̀ khóa: Rùng thứ sinh, thảm thục vật, thảm cây bụi, thảm cỏ, huyện Vị Xuyên.

\section{ABSTRACT}

In the 3 types of vegetation covers (grass vegetation, shrub vegetation and second forest there are 557 species belonging to 393 genera, 114 families of five branches of higher vascular plants such as Lycopodiophyta, Equisetopsida, Polypodiophyta, Pinophyta and Magnoliophyta. Of which, there are 15 families available over 10 species (accounting for $42.01 \%$ of total species), 13 genera available over 4 species (accounting for 12.39\% of total species). There are 33 rare plant species in the 2007 Vietnam Red Data Book and 7 species recorded in Decree of Government No. 32. Majority of statistical species are the light-demanding pioneer species growing on land exploited exhaustedly and on the area of forests without trees after large trees cut down. Although there is a rich and diversified flora, the vegetations in Vi Xuyen district is significant degradation in terms of area and quality that the main reasons is due to the activities of exploitation on logging, firewood and non-timber forest products and forest fire, etc.

Keywords: Secondary forests, vegetation, shrub, grass, Vi Xuyen district.

\section{Đặt vấn đề}

Huyện Vị Xuyên nằm trong vùng núi thấp của tỉnh Hà Giang với đặc điểm khí hậu, địa hình, thổ nhưỡng đa dạng, diện tích rừng tương đối lớn (tổng diện tích rừng là 102.072,06 ha và độ che phủ là 68\%). Trong đó có một phần diện tích rừng nằm trong Khu bảo tồn thiên nhiên Tây Côn Lĩnh và các Khu bảo tồn rừng đặc dụng Phong Quang, Du Già, Khau Ca nên thành phần thực vật khá phong phú và đa dạng với nhiều loài cây gỗ quý như: Lát hoa (Chukrasia tabularis), Nghiến (Excentrodendron tonkinense), Pơ mu (Fokiennia hodginsii), Đinh (Markhamia stipulata)... Tuy nhiên, trong những năm qua mặc dù đã có chính sách giao đất, giao rừng đến từng hộ gia đình của 
Chính phủ, nhưng do dân số tăng nhanh, do nhu cầu cuộc sống hàng ngày... nên nhiều diện tích rừng bị khai thác cạn kiệt làm cho rừng ngày càng bị suy thoái nghiêm trọng.

\section{Đối tượng và phương pháp nghiên cứu}

\section{Đối tượng nghiên cứu}

Các kiểu thảm thực vật ở huyện Vị Xuyên, tỉnh Hà Giang gồm: Thảm cỏ, thảm cây bụi và rừng thứ sinh.

\section{Phương pháp nghiên cứu}

Phương pháp thu thập số liệu trực tiếp ngoài thực địa trên các tuyến điều tra (TĐT) và ô tiêu chuẩn (OTC). Trong mỗi kiểu thảm bố trí tuyến điều tra thứ nhất có hướng vuông góc với đường đồng mức cơ bản, các tuyến sau song song với tuyến điều tra thứ nhất. Khoảng cách giữa hai tuyến tùy theo từng kiểu thảm và địa hình cụ thể, dao động từ $50-100 \mathrm{~m}$, chiều rộng tuyến điều tra là $2 \mathrm{~m}$ về mỗi phía đối với rừng thứ sinh, thảm cây bụi và $1 \mathrm{~m}$ về mỗi phía đối với thảm cỏ. Trên mỗi TĐT tiến hành lập các ô tiêu chuẩn và được phân bố đồng đều ở trong từng kiểu thảm thực vật. Diện tích OTC đối với rừng thứ sinh là $400 \mathrm{~m}^{2}(20 \mathrm{~m} \times 20 \mathrm{~m})$, đối với thảm cây bụi là $16 \mathrm{~m}^{2}(4 \mathrm{~m} \times 4 \mathrm{~m})$, còn đối với thảm cỏ là $1 \mathrm{~m}^{2}$ (1m x $1 \mathrm{~m})$. Trên TĐT và OTC quan sát và ghi chép tất cả các số liệu về thành phần loài (tên Latin hoặc tên địa phương) và dạng sống của các loài thực vật. Những loài chưa biết tên lấy mẫu về định loại.

Xác định tên khoa học, tên địa phương các loài cây theo tài liệu "Cây cỏ Việt Nam" của Phạm Hoàng Hộ (1991-1993) [5], theo "Danh lục các loài thực vật Việt Nam” của Nguyễn Tiến Bân (chủ biên) và cộng sự $(2003,2005)$ [1] và theo cuốn “Tên cây rừng Việt Nam” của Bộ Nông nghiệp và Phát triển Nông thôn (2000) [3]. Xác định những loài thực vật quý hiếm dựa vào Sách Đỏ Việt Nam, 2007 (Phần thực vật) [2] và Nghị định 32/2006/NĐ-CP của Chính phủ, 2006 [4]¹.

\section{Kết quả nghiên cứu}

\section{Đa dạng thành phần thực vật trong một số kiểu thảm ở huyện Vị Xuyên, tỉnh Hà Giang}

\section{Đa dạng ở múc độ ngành}

Tại 3 kiểu thảm thực vât chúng tôi đã thống kê được 557 loài thuộc 393 chi, 114 họ của 5 ngành thực vật bậc cao có mạch. Kết quả được trình bày ở bảng 1 .

\begin{tabular}{|c|c|c|c|c|c|c|c|}
\hline \multirow{2}{*}{ STT } & \multirow{2}{*}{ NGÀNH } & \multicolumn{2}{|c|}{ Họ } & \multicolumn{2}{c|}{ Chi } & \multicolumn{2}{c|}{ Loài } \\
\cline { 3 - 8 } & $\begin{array}{c}\text { Số } \\
\text { lượng }\end{array}$ & $\begin{array}{c}\text { Tỷ lệ } \\
(\%)\end{array}$ & $\begin{array}{c}\text { Số } \\
\text { lượng }\end{array}$ & $\begin{array}{c}\text { Tỷ lệ } \\
(\%)\end{array}$ & $\begin{array}{c}\text { Số } \\
\text { lượng }\end{array}$ & $\begin{array}{c}\text { Tỷ lệ } \\
(\%)\end{array}$ \\
\hline 1 & $\begin{array}{c}\text { Thông đất } \\
\text { (Lycopodiophyta) }\end{array}$ & 2 & 1,75 & 3 & 0,76 & 5 & 0,90 \\
\hline 2 & $\begin{array}{c}\text { Cỏ tháp bút } \\
\text { (Equisetophyta) }\end{array}$ & 1 & 0,88 & 1 & 0,25 & 2 & 0,36 \\
\hline 3 & $\begin{array}{c}\text { Dương xî } \\
\text { (Polypodiophyta) }\end{array}$ & 6 & 5,26 & 9 & 2,29 & 12 & 2,15 \\
\hline 4 & $\begin{array}{c}\text { Thông } \\
\text { (Pinophyta) }\end{array}$ & 3 & 2,63 & 4 & 1,02 & 6 & 1,08 \\
\hline 5 & $\begin{array}{c}\text { Mộc lan } \\
\text { (Magnoliophyta) }\end{array}$ & 102 & 89,48 & 376 & 95,66 & 532 & 95,51 \\
\hline & Cộng & $\mathbf{1 1 4}$ & $\mathbf{1 0 0 , 0 0}$ & $\mathbf{3 9 3}$ & $\mathbf{1 0 0 , 0 0}$ & $\mathbf{5 5 7}$ & $\mathbf{1 0 0 , 0 0}$ \\
\hline
\end{tabular}

Bảng 1: Sự phân bố của các taxon thực vật ở khu vục nghiên cứu (KVNC)

${ }^{1}$ [1],[2],[3],[4] : Số thứ tụ tài liệu tham khảo trong bài viết 
Theo số liệu ở bảng 1, bước đầu đã ghi nhận 5 ngành thực vật bậc cao có mạch, nhưng thành phần thực vật trong các bậc taxon là không đồng đều. Trong 5 ngành thực vật, thì ngành Mộc lan (Magnoliophyta) có số họ, số chi và số loài phong phú nhất: 102 họ $(89,48 \%), 376$ chi (95,66\%), 532 loài $(95,51 \%)$. Tiếp đến là ngành Dương xỉ (Polypodiophyta) có 6 họ $(5,26 \%), 9$ chi $(2,29 \%)$ và 12 loài $(2,15 \%)$, ngành Thông (Pinophyta) có 3 họ $(2,63 \%), 4$ chi $(1,02 \%)$ và 6 loài $(1,08 \%)$, ngành Thông đất (Lycopodiophyta) có 2 họ (1,75\%), 3 chi $(0,76 \%), 5$ loài $(0,90 \%)$. Ngành Cỏ Tháp bút (Equisetophyta) có số họ, số chi và số loài thấp nhất: 1 họ $(0,88 \%), 1$ chi $(0,25 \%), 2$ loài $(0,36 \%)$.

Trong ngành Mộc lan (Magnoliophyta), lớp Mộc lan (Magnoliopsida) có 88 họ (86,27\%), 330 chi $(87,77 \%)$ và 477 loài $(89,66 \%)$. Số lượng của các họ, chi và loài trong lớp này lớn hơn rất nhiều so với lớp Hành (Liliopsida) có 14 họ, 46 chi và 55 loài. Kết quả được trình bày ở bảng 2.

\begin{tabular}{|c|c|c|c|c|c|c|}
\hline \multirow{2}{*}{$\begin{array}{c}\text { Ngành Mộc lan } \\
\text { (Magnoliophyta) }\end{array}$} & \multicolumn{2}{|c|}{ Họ } & \multicolumn{3}{c|}{ Chi } & Loài \\
\cline { 2 - 7 } & $\begin{array}{c}\text { Số } \\
\text { lưọng }\end{array}$ & $\begin{array}{c}\text { Tỷ lệ } \\
(\mathbf{\%})\end{array}$ & Số lượng & $\begin{array}{c}\text { Tỷ lệ } \\
(\%)\end{array}$ & Số lượng & Tỷ lệ (\%) \\
\hline $\begin{array}{c}\text { Lớp Mộc lan } \\
\text { (Magnoliopsida) }\end{array}$ & 88 & 86,27 & 330 & 87,77 & 477 & 89,66 \\
\hline $\begin{array}{c}\text { Lớp Hành } \\
\text { (Liliopsida) }\end{array}$ & 14 & 13,73 & 46 & 12,23 & 55 & 9,34 \\
\hline Tổng & $\mathbf{1 0 2}$ & $\mathbf{1 0 0 , 0 0}$ & $\mathbf{3 7 6}$ & $\mathbf{1 0 0 , 0 0}$ & $\mathbf{5 3 2}$ & $\mathbf{1 0 0 , 0 0}$ \\
\hline
\end{tabular}

Bảng 2: Số lượng họ, chi và loài trong ngành Mộc lan ở KVNC

\section{Đa dạng ở mức độ ho}

Ở các kiểu thảm thực vật chúng tôi đã thống kê được 114 họ. Trong đó họ có số loài nhiều nhất là họ Thầu dầu (Euphorbiaceae) với 40 loài (chiếm 7,18\% tổng số loài), sau đó đến họ Đậu (Fabaceae) có 23 loài, họ Dâu tằm (Moraceae) có 19 loài, họ Hoà thảo (Poaceae) có 17 loài, họ Long não (Lauraceae), họ Cà phê (Rubiaceae) và họ Cúc (Asteraceae) đều có 15 loài, các họ Na (Annonaceae), Trúc đào (Apocynaceae), họ Ngũ gia bì (Araliaceae) và họ Vang (Caesalpiniaceae) có 12 loài, họ Trinh nữ (Mimosaceae) và họ Cỏ roi ngựa (Verbenaceae) có 11 loài, họ Xoan (Meliaceae) và họ Đơn nem (Myrsinaceae) có 10 loài, họ Dẻ (Fagaceae) và họ Cam (Rutaceae) có 9 loài. Ngoài ra 5 họ có 8 loài là họ Hoa môi (Lamiaceae), họ Hoa hồng (Rosaceae), họ Trôm (Sterculiaceae), họ Đay (Tiliaceae) và họ Lan (Orchidaceae); 3 họ có 7 loài là: họ Ô rô (Acanthaceae), họ Bồ hòn (Sapindaceae) và họ Nho (Vitaceae); 6 họ có 6 loài, 9 họ có 5 loài; 11 họ có 4 loài; 16 họ có 3 loài; 22 họ có 2 loài. Có 24 họ chỉ có duy nhất một loài như: họ Ráng mạc điệp (Hymenophyllaceae), họ Sau sau (Altingiaceae), họ Vòi voi (Boraginaceae), họ Kẹn (Hippocastanaceae)... Trong 114 họ đã gặp ở khu vực nghiên cứu, thì có 15 họ có từ 10 loài trở lên (chiếm 42,01\% tổng số loài). Số lượng họ có từ 10 loài trở lên được thống kê ở bảng 3. 


\begin{tabular}{|c|c|c|c|c|}
\hline \multirow{2}{*}{ STT } & \multicolumn{2}{|c|}{ Tên họ } & \multirow{2}{*}{ Số loài } & \multirow{2}{*}{ Tỷ lệ (\%) } \\
\hline & Tên khoa học & Tên Việt Nam & & \\
\hline 1 & Euphorbiaceae & Họ Thầu dầu & 40 & 7,18 \\
\hline 2 & Fabaceae & Họ Đậu & 23 & 4,13 \\
\hline 3 & Moraceae & Họ Dâu tằm & 19 & 3,41 \\
\hline 4 & Poaceae & Họ Hoà thảo & 17 & 3,05 \\
\hline 5 & Lauraceae & Họ Long não & 15 & 2,69 \\
\hline 6 & Rubiaceae & Họ Cà phê & 15 & 2,69 \\
\hline 7 & Asteraceae & Họ Cúc & 15 & 2,69 \\
\hline 8 & Annonaceae & $\mathrm{Họ} \mathrm{Na}$ & 12 & 2,15 \\
\hline 9 & Apocynaceae & Họ Trúc đào & 12 & 2,15 \\
\hline 10 & Araliaceae & Họ Ngũ gia bì & 12 & 2,15 \\
\hline 11 & Caesalpiniaceae & Họ Vang & 12 & 2,15 \\
\hline 12 & Mimosaceae & Họ Trinh nữ & 11 & 1,97 \\
\hline 13 & Verbenaceae & Họ Cỏ roi ngựa & 11 & 1,97 \\
\hline 14 & Meliaceae & Họ Xoan & 10 & 1,80 \\
\hline 15 & Myrsinaceae & Họ Đơn nem & 10 & 1,80 \\
\hline \multicolumn{3}{|c|}{ Tổng } & 234 & 42,01 \\
\hline
\end{tabular}

Bảng 3: Các họ thục vật có tù 10 loài trở lên ở khu vục nghiên cúu

Phần lớn các loài cây thống kê được đều là các loài tiên phong ưa sáng vì có thể bắt gặp chúng mọc trên đất sau khai thác kiệt, trên các chỗ trống của rừng sau khi những cây gỗ lớn bị chặt hạ.

Các loài cây gỗ lớn có giá trị kinh tế hoặc giá trị sử dụng cao như: Lát hoa (Chukrasia tabularis), Nghiến (Parapentace tonkinense), Re hương (Cinnamomun parthenoxylon), Giổi xanh (Michelia mediocris)... còn lại rất ít. Nguyên nhân của tình trạng này là do rừng tự nhiên bị tàn phá nặng nề, nguồn giống bị thiếu hụt làm giảm khả năng tái sinh của cây con. Do vậy, trong quá trình phục hồi cần có những biện pháp bảo vệ, gây trồng hoặc xúc tiến tái sinh tự nhiên để bảo tồn nguồn gen.

\section{Đa dạng ở múc độ chi}

Tại KVNC đã thống kê được 393 chi thực vật. Chi có nhiều loài nhất là Ficus với 12 loài chiếm $2,15 \%$ tổng số loài. Tiếp theo là chi Fissistigma có 6 loài ( $1,08 \%$ tổng số loài); 3 chi có 5 loài là Mallotus, Lithocarpus, Clerodendrum; 9 chi có 4 loài là Schefflera, Garcinia, Dillenia, Elaeocarpus, Phyllanthus, Castanopsis, Acacia, Maesa, Rubus. Có 13 chi có từ 4 loài trở lên, các chi này có 69 loài (12,39\% tổng số loài). Ngoài ra có 21 chi có 3 loài, 58 chi có 2 loài và 233 chi chỉ có một loài. Số lượng chi có từ 10 loài trở lên được thống kê ở bảng 4. 


\begin{tabular}{|c|c|c|c|c|c|}
\hline \multirow{2}{*}{ STT } & \multirow{2}{*}{ Tên chi } & \multicolumn{2}{|c|}{ Ho } & \multirow{2}{*}{ Số loài } & \multirow{2}{*}{$\begin{array}{c}\text { Tỷ lệ } \\
(\%)\end{array}$} \\
\hline & & Tên khoa học & Tên Việt Nam & & \\
\hline 1 & Ficus & Moraceae & Họ Dâu tằm & 12 & 2,15 \\
\hline 2 & Fissistigma & Annonaceae & $\mathrm{Họ} \mathrm{Na}$ & 6 & 1,08 \\
\hline 3 & Mallotus & Euphorbiaceae & Họ Thầu dầu & 5 & 0,90 \\
\hline 4 & Lithocarpus & Fagaceae & Họ Dẻ & 5 & 0,90 \\
\hline 5 & Clerodendrum & Verbenaceae & Họ Cỏ roi ngựa & 5 & 0,90 \\
\hline 6 & Schefflera & Araliaceae & Họ Ngũ gia bì & 4 & 0,72 \\
\hline 6 & Garcinia & Clusiaceae & Họ Bứa & 4 & 0,72 \\
\hline 7 & Dillenia & Dilleniaceae & Họ Sổ & 4 & 0,72 \\
\hline 8 & Elaeocarpus & Elaeocarpaceae & Họ Côm & 4 & 0,72 \\
\hline 9 & Phyllanthus & Euphorbiaceae & Họ Thầu dầu & 4 & 0,72 \\
\hline 10 & Castanopsis & Fagaceae & Họ Dẻ & 4 & 0,72 \\
\hline 11 & Acacia & Mimosaceae & Họ Trinh nữ & 4 & 0,72 \\
\hline 12 & Maesa & Myrsinaceae & Họ Đơn nem & 4 & 0,72 \\
\hline 13 & Rubus & Rosaceae & Họ Hoa hồng & 4 & 0,72 \\
\hline \multicolumn{4}{|c|}{ Tổng } & 69 & 12,39 \\
\hline
\end{tabular}

Bảng 4: Các chi thục vật có tù̀ 4 loài trở lên ở KVNC

\section{Các loài thực vật quý hiếm²}

Trong tổng số 557 loài tại khu vực nghiên cứu, chúng tôi đã thống kê được 33 loài thực vật quý hiếm có trong Sách đỏ Việt Nam, chiếm 7,12\% số loài có trong Sách đỏ Việt Nam (2007) [2], trong đó có 1 loài thuộc nhóm rất nguy cấp (CR); 12 loài thuộc nhóm nguy cấp (EN); 20 loài thuộc nhóm sẽ nguy cấp (VU); 7 loài trong nghị định 32/2006 NĐ-CP [4] chiếm $1,26 \%$ tổng số loài đã biết tại khu vực nghiên cứu và chiếm $13,46 \%$ tổng số loài có tên trong Nghị định 32/2006 NĐ-CP, trong đó 2 loài nằm trong nhóm I.A và 5 loài nằm ở nhóm II.A. Các loài thực vật quý hiếm được thống kê ở bảng 5.

\section{${ }^{2}$ Ghi chú:}

- SĐVN 2007: Sách đỏ Việt Nam, 2007. Trong đó: CR là rất nguy cấp; EN là nguy cấp; VU là sẽ nguy cấp.

- NĐ số 32/2006 NĐ-CP: Nghị định của Chính phủ ban hành ngày 30/3/2006 của Chính phủ về quản lý thực vật rùng, động vật rùng, thực vật rùng nguy cấp, quý, hiếm trong đó: Nhóm I.A cần nghiêm cấm khai thác, sử dụng vì mục đích thuơng mại; Nhóm II.A cần hạn chế khai thác, sủ dụng vì mục đích thưong mại. 


\begin{tabular}{|c|c|c|c|c|}
\hline STT & Tên khoa học & Tên Việt Nam & $\begin{array}{c}\text { SPVN } \\
2007\end{array}$ & $\begin{array}{c}\text { ND } 32 \\
2006\end{array}$ \\
\hline 1 & Annamocarya sinensis (Dode) J. Leroy & Chò đãi & EN & \\
\hline 2 & Anoectochilus calcareus Aver. & Kim tuyến đá vôi & EN & I.A \\
\hline 3 & Aquilaria crassna Pierre ex Lecomte & Trầm hương & EN & \\
\hline 4 & Ardisia silvestris Pitard & Lá khôi & VU & \\
\hline 5 & Canarium tramdenum Dai \& Yakov. & Trám đen & VU & \\
\hline 6 & Castanopsis hystrix A. DC. & Dẻ gai đỏ & VU & \\
\hline 7 & Castanopsis lecomtei Hickel \& A. Camus & Cà ổi Sa pa & VU & \\
\hline 8 & Cinnadenia paniculata (Hook. f.) Koesterm & Kháo xanh & $\mathrm{VU}$ & \\
\hline 9 & Cinnamomum balansae Lecomte & Gù hương & VU & II.A \\
\hline 10 & Cinnamomum parthenoxylon (Jack.) Meisn. & Re hương & $\mathrm{CR}$ & II.A \\
\hline 11 & Chukrasia tabularis A. Juss. & Lát hoa & VU & \\
\hline 12 & Dalbergia tonkinensis Prain & Sưa & VU & I.A \\
\hline 13 & Drynaria fortunei (Kuntze.) J. Smith & Cốt toái bổ & $\mathrm{EN}$ & \\
\hline 14 & Excentrodendron tonkinense (Gagnep.) Chang \& Miau & Nghiến & EN & II.A \\
\hline 15 & Fallopia multiflora (Thunb.) Haraldson & Hà thủ ô đỏ & VU & \\
\hline 16 & Garcinia fagraeoides A. Chev. & Trai lý & $\mathrm{EN}$ & II.A \\
\hline 17 & Goniothalamus vietnamensis L. & Béo đen & VU & \\
\hline 18 & Gymnostemma pentaphyllum (Thunb.) Makino & Dần toòng & $\mathrm{EN}$ & \\
\hline 19 & Leucosceptrum canum Smith & Hoa bông & $\mathrm{EN}$ & \\
\hline 20 & Madhuca pasquieri (Dubard) H. J. Lam & Sến mật & EN & \\
\hline 21 & Manglietia fordiana Oliv & Vàng tâm & VU & \\
\hline 22 & Markhamia stipulata (Wall.) Seem. ex Schum. & Đinh & VU & II.A \\
\hline 23 & Melientha suavis Pierre & Rau sắng & VU & \\
\hline 24 & Michelia balansae Dandy & Giổi lông & $\mathrm{VU}$ & \\
\hline 25 & Morinda officinalis How & Ba kích & $\mathrm{EN}$ & \\
\hline 26 & Rauvolfia latifrons Tsiang & Ba gạc lá to & VU & \\
\hline 27 & Strophanthus wallichii A. DC. & Sừng trâu & EN & \\
\hline 28 & Tetrapanax papyriferus (Hook.) C. Koch. & Thông thảo & $\mathrm{EN}$ & \\
\hline 29 & Paramichelia baillonii (Pierre.) S. Y. Hu & Giổi găng & VU & \\
\hline 30 & Parashorea chinensis $\mathrm{H}$. Wang & Chò chỉ & VU & \\
\hline 31 & Taxillus gracilifolius (Schult. f.) Ban & Mộc vệ rủ & VU & \\
\hline 32 & Tinospora sagittata (Oliv.) Gagnep & Củ gió & VU & \\
\hline 33 & Valeriana execta Merr. & Nữ lang & VU & \\
\hline
\end{tabular}

Bảng 5: Danh lục các loài thực vật quý hiếm ở KVNC 


\section{Các nguyên nhân làm suy thoái rù̀ng ở huyện Vị Xuyên tỉnh Hà Giang}

\section{Hoạt động khai thác gỗ}

Hoạt động khai thác gỗ trong vùng rừng đặc dụng, rừng phòng hộ và rừng đầu nguồn ở Hà Giang diễn ra gay gắt trong vòng 4 - 5 năm trở lại đây. Do lợi nhuận từ khai thác gỗ Nghiến, Đinh lên tới vài triệu đồng/người/ngày nên các đối tượng lâm tặc bất chấp thủ đoạn để tàn phá rừng. Hàng trăm, thậm chí hàng nghìn cây gỗ Nghiến, Trai (nhóm IIA) cổ thụ có đường kính từ 0,8 $1,5 \mathrm{~m}$ đã bị đốn hạ, cắt thớt trong sự bất lực của các cơ quan chức năng. Hàng năm, lượng gỗ tịch thu được chỉ là một phần rất nhỏ so với lượng gỗ đã khai thác. Đây là nguyên nhân quan trọng làm cho chất lượng của rừng bị suy thoái.

\section{Khai thác lâm sản khác ngoài gỗ}

- Khai thác củi: do thu nhập của đa số các hộ dân trong huyện còn thấp và theo thói quen sinh hoạt nên củi được sử dụng làm chất đốt là chủ yếu. Ngoài ra, những hộ gia đình nghèo không có đất sản xuất, không có vốn đầu tư đã vào rừng khai thác củi để bán nhằm tăng thêm thu nhập cho gia đình. Lượng củi khai thác giai đoạn 2010 - 2013 ở huyện Vị Xuyên dao động 136.820 - 227.780 ster/năm.

- Khai thác lâm sản ngoài gỗ khác: số liệu bảng 4.8 cho thấy, có nhiều loại lâm sản ngoài gỗ đã bị khai thác ở huyện Vị Xuyên (14 loại), trong đó khai thác tre, nứa, luồng 238.000 - 339.300 cây/năm; khai thác nứa, trúc, giang 143.000 - 316.680 cây/năm; bông chít 56 - 65 tấn/năm; thảo quả 636 - 830 tấn/năm; măng tươi 38 - 113 tấn/năm... Tất cả các loài trên đều được sử dụng trong hộ gia đình, bán và xuất khẩu qua biên giới với lợi nhuận cao, nên tình trạng khai thác diễn ra khá phổ biến. Ngoài ra, thú rừng cũng bị săn bắt để làm thực phẩm, dược phẩm cũng diễn ra khá phổ biến.

Do vậy, khai thác lâm sản ngoài gỗ cũng là một trong các nguyên nhân làm suy kiệt tài nguyên đa dạng sinh học của rừng.

\section{Cháy rùng}

Đây là nguyên nhân làm suy thoái tài nguyên rừng một cách nhanh chóng nhất, gây ảnh hưởng tới các hoạt động sống của sinh vật trên một diện tích rộng lớn và gây ra các hậu quả xấu (xói mòn, lũ lụt, hạn hán...) đến đời sống con người. Nguyên nhân chủ yếu của cháy rừng là do hoạt động khai thác của con người như: đốt nương làm rẫy, đốt các gốc cây to để khai thác than gỗ, đốt lửa lấy mật ong... Ngoài ra cháy rừng còn do nguyên nhân thời tiết nắng nóng kéo dài (tháng 6 , $7,8,9)$ với nhiệt độ trung bình trên $28^{\circ} \mathrm{C}$ và số giờ nắng trung bình 155,26 giờ. Theo kết quả thống kê của hạt kiểm lâm huyện Vị Xuyên giai đoạn từ năm 2005 - 2012, toàn huyện có 28 vụ cháy rừng với diện tích rừng bị cháy là 750,2 ha.

\section{Các nguyên nhân khác}

Lực lượng kiểm lâm tỉnh Hà Giang nói chung và huyện Vị Xuyên nói riêng còn quá mỏng so với quy định, các trang thiết bị, phương tiện phục vụ cho quản lý bảo vệ rừng còn thiếu thốn.

Tỷ lệ tăng dân số của huyện còn khá cao $(1,2 \%)$, đời sống nhân dân còn gặp nhiều khó khăn (tỷ lệ hộ nghèo năm 2013 là 21,77\%). Vì vậy, đời sống kinh tế còn phụ thuộc nhiều vào khai thác tài nguyên rừng.

Trình độ dân trí thấp nên khó tiếp cận với các chương trình dự án về rừng, nhận thức của người dân về tác hại của việc khai thác quá mức tài nguyên rừng còn hạn chế. 
Công tác tuyên truyền phổ biến, giáo dục chính sách pháp luật cho nhân dân tuy đã được triển khai nhưng chưa thường xuyên, kịp thời.

Do phong tục, tập quán đã có từ lâu đời như: du canh du cư, phải sinh con trai hay chăn thả gia súc vào rừng nên đã làm cho tài nguyên rừng bị suy giảm.

Chưa có chính sách thưởng, phạt rõ ràng nên chưa có tác dụng động viên người dân tích cực tham gia bảo vệ rừng.

\section{Kết luận}

Hệ thực vật huyện Vị Xuyên có thành phần thực vật phong phú và đa dạng gồm 557 loài thuộc 393 chi, 114 họ của 5 ngành thực vật bậc cao có mạch: ngành Thông đất, ngành Cỏ tháp bút, ngành Dương xỉ, ngành Thông và ngành Ngọc lan. Trong đó có 33 loài thực vật quý hiếm có trong Sách đỏ Việt Nam (2007) và 7 loài được ghi nhận trong Nghị định 32 của Chính phủ.

Các hoạt động khai thác gỗ, khai thác lâm sản ngoài gỗ và cháy rừng là những nguyên nhân chính làm suy giảm diện tích và chất lượng thảm thực vật rừng ở huyện Vị Xuyên.

\section{TÀI LIỆ THAM KHẢO}

1. Nguyễn Tiến Bân (chủ biên) và cộng sự (2003, 2005), Danh lục các loài thực vật Việt Nam, Nxb Nông nghiệp, Hà Nội.

2. Bộ Khoa học và Công nghệ, Viện Khoa học và Công nghệ Việt Nam (2007), Sách đỏ Việt Nam (phần Thực vật), Nxb Khoa học Tự nhiên và Công nghệ, Hà Nội.

3. Bộ Nông nghiệp và Phát triển Nông thôn (2000), Tên cây rùng Việt Nam, Nxb Nông nghiệp, Hà Nội.

4. Chính phủ nước Cộng hoà xã hội chủ nghĩa Việt Nam (2006), Nghị định 32/2006/NĐ-CP về quản lý thực vật rù̀ng, động vật rù̀ng nguy cấp, quý, hiếm, Hà Nội.

5. Phạm Hoàng Hộ (1991-1993), Cây cỏ Việt Nam, tập I - III, Nxb Motreal, Canada. 